\title{
Making Sense of 3D Modelling and 3D Printing Activities of Young People
}

\author{
Behnaz Norouzi \\ INTERACT Research Unit, \\ University of Oulu, Finland \\ Behnaz.norouzi@oulu.fi
}

\author{
A Nexus Analytic Inquiry
}

\author{
Netta Iivari \\ INTERACT Research Unit, \\ University of Oulu, Finland \\ Netta.iivari@oulu.fi
}

\begin{abstract}
Physical space and materials we work with, as well as people we interact with affect the design and making processes. These aspects in relation to 3D designing in alignment with 3D printing need considerable exploration within Child-Computer interaction (CCI) research community. We conducted our case study by collecting 9-full-day-observation and interview data and examining 3D modeling and 3D printing activities, as work duties of 15-17-yearsold summer trainees organized at the university. We identified, inspired by nexus analysis, different discourses circulating around these activities of novice young people and how the discourses are intermingled with the space, the materials, and the task at hand in complex ways, constructing and shaping the experience of the young participants. In our research and design implications, by signifying the impact of the people, challenges, tasks, spaces and tools, we provide recommendations for maintaining children's engagement in digital fabrication, significantly $3 \mathrm{D}$ designing and $3 \mathrm{D}$ printing, activities.
\end{abstract}

\section{CCS CONCEPTS}

- Human-centered computing; • Human computer interaction (HCI); • Empirical studies in HCI;

\section{KEYWORDS}

Children, Teenager, Technology, 3D modeling/designing, 3D printing, FabLab, Maker space, Making, Digital fabrication, Nexus analysis, Discourse analysis, Qualitative study, Empirical finding

ACM Reference Format:

Behnaz Norouzi, Marianne Kinnula, and Netta Iivari. 2021. Making Sense of 3D Modelling and 3D Printing Activities of Young People: A Nexus Analytic Inquiry. In CHI Conference on Human Factors in Computing Systems (CHI '21), May 08-13, 2021, Yokohama, Japan. ACM, New York, NY, USA, 16 pages. https://doi.org/10.1145/3411764.3445139

\section{INTRODUCTION}

There is a wide agreement that teaching digital fabrication and making skills to children and young people is useful for them. A

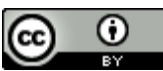

This work is licensed under a Creative Commons Attribution International 4.0 License.

CHI '21, May 08-13, 2021, Yokohama, Japan

(c) 2021 Copyright held by the owner/author(s).

ACM ISBN 978-1-4503-8096-6/21/05.

https://doi.org/10.1145/3411764.3445139 large number of attempts to teach these skills have been identified not only during children's leisure time (see [68]), but also within the K-12 curriculum (see e.g., [12]), and even as integrated activities in K-12 curriculum in some countries either officially or in practice (see e.g., [53, 88, 89]). A large research base exists on the topic, spanning multiple disciplines and research fields. Our focus is particularly on 3D modelling and 3D printing activities, which form a common subset of digital fabrication process introduced to children. With digital fabrication we refer to "a design and manufacturing workflow where digital data directly drives manufacturing equipment to form various part geometries. This data most often comes from CAD (computer-aided design), which is then transferred to CAM (computer-aided manufacturing) software. The output of CAM software is data that directs a specific machine, like a 3D printer or CNC milling machine." [16]. Making is associated with finding resonance not only with material but also with people [82] where "Do it yourself" (DIY) is a cultural movement [48], which empowers people to productively and tangibly engage in the world [27].

Significance of 3D modeling and 3D printing has already been acknowledged within Human Computer Interaction (HCI) research (see e.g., $[4,20,28-31,93])$ as well as in connection to a diversity of research topics, such as: the potentials of using 3D printers as well as other fabrication devices in the home [81]; selfemployment opportunities for adults with intellectual disabilities [11]; fostering an understanding of social and civic responsibilities and human rights via E-making 3D printing [57]; learning about sustainability [57]; and the role of libraries as lawmakers for 3D printing activities [92]. Our study focuses specifically on young people, who as a participant group has been extensively involved in Child-Computer Interaction (CCI) research. 3D modeling and 3D printing have already been recognized as important topics of study in relation to young people as well (e.g., $[4,10,11,17,20,22,28,31,32,41,43,49,51,54,56,63,66,75,85,93])$.

Despite the wide-ranging interest, there still remains a number of research gaps and limitations in the existing research. There are calls for more research on understanding children's (self-directed) interactions with digital fabrication technologies $[29,70]$; more intuitive interfaces [70]; how 3D printing should be developed as a technology which is powerful, rich and challenging [18]; how to leverage $3 \mathrm{D}$ printing to benefit the arena of special education [10]; how to accommodate the 3D modeling platforms for the use of novice learners [85]; socio-technical problems in 3D printing [84]; explicit realities about 3D printing challenges [64]; and how to introduce the complexities of $3 \mathrm{D}$ printing process to young people [3]. This study responds to these calls for research by extending our 
understanding of young people's experiences of and engagement in 3D modelling and 3D printing- we focus on the complex sociotechnical setting involved and inquire the influence of the physical space and task at hand on the resulting experience. The significance of the material environment in combination with interactions with other participants needs to be realized and addressed stronger in the CCI research.

Thus, in this paper we aim to 'make sense of what happens in the digital fabrication process when young people engage in $3 D$ designing and $3 D$ printing activities, and how the physical environment and the given task affect their interactions and engagement'. We examine this through a case study on a summer trainee program organized at the university involving teenagers within the ages of 15 to 17 years old. Teenagers are a participant group that has already aroused CCI researchers' interest (see e.g., [39, 71, 72]); it is indicated that they are in many respects a different participant group to younger children. We extend this literature by analyzing a case in which the teenagers are involved in summer job; hence, moving towards the adult world, and at the same time getting familiarized with digital fabrication and making. In the analysis, we apply the theoretical lens of nexus analysis (e.g., [78]), which is a suitable lens for making sense of the complex topics involving constellations of people, tools, materials and spaces, with discourses circulating around (see e.g., $[33,34])$.

\section{RELATED RESEARCH}

\subsection{Research on 3D Modelling and 3D Printing}

CCI research, which gets inspiration from multiple research disciplines while mainly from HCI [73], has already been interested in how to introduce and integrate 3D modelling and 3D printing into children's everyday lives and practices; studies have been conducted in the both informal and formal learning settings (see e.g., $[12,13,38,68,83,87])$. In many CCI studies, 3D modelling and $3 \mathrm{D}$ printing activities have been integrated into a broader design process containing different kinds of digital fabrication and making activities among other activities, while some of the studies focus more specifically on 3D designing and printing. To give some examples, Iversen and colleagues (e.g., $[38,83])$ have developed a model for integrating digital fabrication and making in the educational context that contains six phases: design brief, field study, ideation, fabrication, argumentation and reflection [38]. Bekker et al. [1] have created a framework called reflective design-based learning (RDBL) inspired by Gomez et al. [26] design-based learning model that includes digital fabrication and making activities as well. Chu and colleagues (e.g., [12]) have experimented with curriculum-aligned making in the context of school.

Although providing valuable insights, these studies do not focus specifically on 3D modelling and 3D printing activities of children. Some studies specific on these activities can also be found. A five step Casual Makers' 3D Printing Workflows has been proposed: 1. Plan the 3D Object, 2. Step 2A: Create a 3D Model; Step 2B: Download a 3D Model, 3. Set up the Printer, 4. Verify the Model, 5. Print the Model [30]. The model has been relied on in studies analysing 3D modelling and 3D printing activities of children [3].
In addition to identifying guidelines, CCI researchers have been interested in topics in relation to 3D modeling and 3D printing such as the development of child-friendly tools [4, 20, 32, 85], software $[49,51]$, toolkits [43], programming language [41, 93] and even new 3D printing materials for children [31]; cultivating learning for children with disabilities [43]; the importance of prototyping in the design process $[17,22,54,56,63]$; children's confidence enhancement with regards to handling tool-use [22] and learning about modeling and printing [11]; and establishing children's interest in the realm of education in Science, Technology, Engineering, and Mathematics [10, 28, 66, 75].

CCI research has already recognized also many challenges regarding $3 \mathrm{D}$ modelling and $3 \mathrm{D}$ printing by children. It has been reported that screen-based 3D modeling, meaning, learning about three dimensions via a two-dimensional screen, is difficult $[20,51,70]$. Specifying and producing a $3 \mathrm{D}$ form which is suitable for 3D printing is challenging $[30,51]$. Some tools and concepts in 3D modeling software are either difficult to understand [51] and learn [43], or do not fulfil the expectations of children [70]. 3D modeling software also lacks collaboration features [60]. In general, getting started with 3D modeling software is challenging [49], especially when it comes to independent learning [29], and children also encounter difficulties already at the initial stage of brainstorming what to print [3].

Regarding 3D printing itself, it has been reported that there is not enough appropriate support including accessible feedback for the consumers of 3D printing technology compared to the other technologies [10]. There are some user experience and usability issues including lack of collaboration features with the current 3D printers [84]. Moreover, the current 3D printers are relatively slow [11], and $3 \mathrm{D}$ printing is laborious which could lead to disappointment and frustration [63]. There might also be mismatching expectations of the output in relation to the design idea $[3,30]$. Understanding the effect of the model geometry as well as of the print setting on the output may be difficult [30]. User interfaces of the 3D printers are not general and lack reusable values [41]. It does not help that not all the 3D printer operators are trained experts in the domain and able to subtly help children [30]. Evidently, there is a need to study further the topic of 3D modelling and 3D printing with children. This study particularly aims to offer new understandings of the complex socio-technical setting involved and inquire the influence of the physical space and task at hand on the resulting experience.

\subsection{Design Process}

3D modeling and printing can be considered as parts of the creative design process. From our study point of view, particularly interesting element of creative design process emerging from our data was the situated action and the material aspects involved. Materiality of the design process has been understood for a long time; Schön [77], for example, calls design " a reflective conversation with the materials in the situation" (see also [76]). Material objects also provide "border resources for interaction" (see also [8, 40, 80]) for collaboration in cooperative design; Vyas et al. [91] even stress that "material collaboration" is critical for it.

But, the material at hand is not the only factor that affect the process: for Le Dantec [14], design process is not only situated in 
a particular time and place but also in a cultural context (see also [7]). Peschl and Fundneider [69] continue with the same line from the innovation perspective, arguing that "innovation is not only a cognitive activity taking place inside the brain, but it is intrinsically coupled with the environment." They suggest the concept of an Enabling Space, where "architectural/physical, social, cognitive, technological, epistemological, cultural, intellectual, emotional and other factors are considered and integrated, aiming to support innovation activities." Moultrie et al. [61], on their part, argue that the physical space should support both the "process of creation" as well as the "process of use," i.e., the space helps the users of the space in their intended creative activities, whatever they are, and provides the needed resources for the process, taking into account different users of the space. Thoring et al. [86] complement this by providing a typology of design spaces, where they distinguish between personal space, collaboration space, space for giving presentations, space for actual practical work, and spaces that are not originally intended for design work but provide a possibility for breaks of the work. Moultrie et al. [61] stress that when designing a creative space, it is important to consider what the intended use is and how that use can be supported in practice. As an example, they discuss flexible workspaces to improve team communication or physical or visual sources for inspiring design ideas. Finally, Magadley and Birdi [58] identify as significant to the creative process a separate time and place reserved for the process, technology to facilitate the process, and finally, human facilitation for the creative process, with which they refer to facilitation of group work, discussions, and keeping up the spirit, in line with Kristensen [46], who discusses scaffolding the creative process.

Materiality has been underscored in connection to making in CCI research. Making involves creation of material things and engagement with material objects, which are reported to engage and entertain children and facilitate the design and making process in many ways [37]. As to the creative spaces, the literature reports that design and making activities happen both in the educational contexts and in the out-of-the-school settings, including e.g., libraries, museums, youth centers, computer clubs, FabLabs, and universities $[1,3,5,13,19,42,50,55,68,70,83]$. Home use of 3D printers is also becoming more common [60]. However, CCI research is limited in examining exhaustively how the different spaces shape and affect the digital fabrication activities and experiences. One study has highlighted the influence of resources available in the space; they afford and constrain interactions among people and the outcomes of making [55].

Creative space itself has interested CCI researchers. Makhaeva et al. [59], inspired by Peschel and Fundneider's concept of enabling spaces [69], have developed a concept of "Handlungsspielraum," to be used for systematic exploration of design collaboration from theoretical perspective as well as practically helping to support in planning, conducting, and reflecting on the creative design collaboration. In Handlungsspielraum, creative freedom is combined with methodological structures from social, physical and mental perspectives. Lee et al. [52] hypothesize that a careful physical design and layout of the space in a library can invite participation in the offered activities. They argue that we should consider "how people naturally arrange themselves physically into groups," as otherwise the physical arrangement of the space may make children to feel uncomfortable and not allow them to choose with whom they interact with. Furthermore, Kinnula et al. [44] bring forth the significance of the interaction between the group members in the creative action and how it can affect the creative process and its outcome, referring to Goffman $[24,25]$. The significance of groupwork and collaborative learning have also been emphasized in research on 3D designing and/or making with children (see e.g., [17, 84, 90, 94]). In addition, some studies have noted that groupwork in digital fabrication and making activities might: be challenging, require a lot of negotiation, not entail equally shared workload, and be hindered by peer pressure [36, 83].

\subsection{Nexus Analysis as a Theoretical Framework}

In this study, nexus analysis provides the theoretical lens for making sense of young people's digital fabrication and making experiences, with a particular focus on the influence of task and space on the experience. Nexus analysis is a highly multidisciplinary research strategy and theoretical lens, having background and inspiration in linguistics, discourse and interaction studies, anthropology, practice theories, and activity theory, among others [78, 79]. Despite its background in discourse and language studies, however, nexus analysis sees social action as the unit of analysis to be focused upon. Moreover, nexus analysis maintains social action is to be examined as constituted in the intersection of three aspects: historical bodies of the participants, interaction order among them and discourses in place circulating around $[78,79]$. As for all these three aspects, nexus analysis is also interested in materiality intermingled with. The concept of discourses in place emphasizes that the discourses are always emerging in situ, particularly place and time, shaped by its constraints and affordances. A particular space may invite particular discourses as well as embed such, implying that discourses of the past are intimately intertwined with our current actions. Scollon and Scollon [78] use classroom as an example for illustrating how prominent discourses from the past are shaping current action: they are embedded in the classroom arrangement, in the furniture, in the architecture of the school. They give raise to particular discourses in situ, although nexus analysis acknowledges also current societal discourses circulating around any social action as relevant. The discourses and the material setting are involved in shaping interaction order among the participants: the discourses embedded in the space enable some interactions while hinder others [78]. The concept of interaction order, coined by Goffman [25], focuses the attention to social interaction among people being constituted in situ, but acknowledges also the influence of broader social conventions, norms and rules shaping in situ interaction. Third significant concept is historical body of the participants, coined by Nishida [67], closely associated with the concept of habitus by Bourdieu [6]. The concept of historical body is preferred in nexus analysis as it directs attention to actual human bodies, with past experiences, histories and expertise embedded, engaged in any social action $[78,79]$. Nexus analysis, overall, enables "to avoid uprooting words and actions from the historical bodies of the individuals performing them, or disconnecting the discourses and actions from the sociocultural context of their formation and realization, or ignoring the history of these actions and discourses for the individual and in the situation. (...) The individual accumulates experience in the course of his/her trajectory across time and space, social orders open up and close and 
are rearranged, discourses in place are transformed as buildings are refashioned, innovative technologies are introduced, new texts and discourses circulate." [79]. Nexus analysis entails "the mapping of semiotic cycles of people discourses, places, and mediational means involved in the social action" [78].

The social action under study is ' $3 \mathrm{D}$ designing and 3D printing' with young people as focal social actors. The analysis will examine interaction orders and historical bodies of the participants as intermingled with the social action as well as discourses in place, emerging in situ, particularly from the viewpoint of discourses embedded in the physical places.

\section{METHODOLOGY}

\subsection{Interpretive Case Study}

This study represents an interpretive case study. Case studies, in general, examine "a phenomenon in its natural setting, employing multiple methods of data collection to gather information from one or few entities (people, groups, or organizations). The boundaries of the phenomenon are not clearly evident at the outset of the research and no experimental control or manipulation is used." [2]. Interpretive case studies, in particular, aim at understanding and making sense of the world, instead of explaining in the sense of predicting. Interpretive case studies focus on the meanings attached to the phenomenon of interest, on the study participants' perspective and on thorough understandings [15, 45]. The case involved in this study was a university summer trainee program, organized by an electronics and robotics club, with the ultimate goal of getting the 15-17-years-old trainees acquainted and interested in the technological fields and therefore inspiring the potential future applicants for these fields in the university. When applying for the paid summer job, the teens prioritized between the tasks based on their interests; however, according to the final feedback, some had not explicit ideas about what they were applying for. The task topics, which included 3D modeling, 3D printing, Arduino programming, robotics, and VR-game programming, were designed based on 1) a broader category of projects to attract more girls, and 2) defining meaningful pedagogical projects. The participants, who were recruited by the club for this program, worked with the activities assigned to them for nine days, seven hours per day. The most essential recruitment criteria were enthusiasm and willingness. Although girl applicants were prioritized, only $20 \%$ of the recruited trainees were girls. Some girls felt they did not belong due to their small number; some of them, however, including those that we closely observed, were natural with the setting.

In line with case study methodology [2], we did not intervene in the arrangements of the summer trainee program but acted as outsider observers. Hence, we did not affect the participants' recruitment, the task topics or the duration of the program and activities. As this was a paid summer job for the participants, they were obliged to work $7 \mathrm{~h}$ per day for the duration of 2 weeks (1 day happened to be a public holiday).

\subsection{Study Participants}

We reached the trainees via the pedagogical expert for the summer trainee program, who approved and shared our 'participant information \& informed consent form', which included information about: researchers, purpose of the study, the reason for inviting them to our study, the influence of their participation, methods of data collection, ways of using and storing their data, data confidentiality, involved risks in their participation, their rights to withdraw from the study, having access to their data, having rights to appeal, and information of a movie ticket reward for their participation. In addition, the consent form included an obligatory parental consent section for those who were under 18-years-old. Altogether, five trainees as well as two instructors related to their activities and the pedagogical expert of the program took part in this study. We collected very similar type of consent also from our adult participants. The five trainees worked in four different groups: three 3D modeling groups and a 3D printing group (Table 1), with some intergroup collaborations.

\subsection{Data Collection}

Our interpretive case study was carried out by utilizing observation and interview methods, which are suggested as some of the most widely used methods in case studies (e.g. [2]) and are capable of in-depth portraying of the phenomenon [21], wherein their combination helps us learn fruitfully about our participants [78]. We took an interpretive, naturalistic stance, "attempting to make sense of or interpret phenomena in terms of the meanings people bring to them." [15].

Observation. Neutral passive observation was done via taking fieldnotes and photographs for the duration of 9 days. For the sake of first impression management, our only direct interaction with our participants was at the beginning of their activities by saying hi, introducing ourselves, and briefly explaining the reason and manner of our presences therein. In taking observation notes, we brought the focus mainly on the participants' interactions with each other and their instructors, as well as the machines and tools that they were utilizing. Our detailed fieldnotes include the description of the physical setting, what the participants were doing, what was the sequence of the activities, what was the goal of the tasks in hand, who else was involved and how, what actions were taken, what kind of conversations took place, what worked or didn't work, and what feelings and attitudes were evident.

Interviewing. Right after the trainee period, we conducted informal flexible open-ended semi-structured interviews (we emphasized informal discussions rather than formal interviews) with the five trainees, two of their instructors, and the program's pedagogical expert, inquiring their backgrounds, experiences, feelings, environment, reflections on their different activities, and also specifically those events about which we intended to further our knowledge based on our observations. Overall duration of the audio recorded interviews was $5 \mathrm{~h} 37 \mathrm{~min}$ ( $\sim 20 \mathrm{~min} /$ trainee; $80 \mathrm{~min} /$ adult).

We followed general guidelines for the qualitative interview [62] as follows: We allowed the participants to pick the date and location for the interviews; we suggested meeting at the university, which was welcomed by the participants. In order to enjoy a less formal atmosphere, we had chosen a cozy room, as shown in Figure 1, with rocking chairs. Only the researcher and research assistant who were familiar for the trainees were present for the interviews. We asked permission for audio recording our conversations. We tried to show the right amount of empathy in an interested yet 
Table 1: Participants' Information

\begin{tabular}{|c|c|c|c|c|c|c|}
\hline Group & Place & Role & Age & Participant & Gender & Definition \\
\hline \multirow{2}{*}{$\begin{array}{l}\text { Modeling-Grp1: 3D } \\
\text { modeling group 1; } 3 \\
\text { members }\end{array}$} & \multirow[t]{2}{*}{$\begin{array}{l}\text { University } \\
\text { FabLab }\end{array}$} & \multirow{2}{*}{$\begin{array}{l}\text { 3D modeling and rapid } \\
\text { prototyping; collaboration with } \\
\text { Printing-Grp for getting } \\
\text { designed objects 3D printed }\end{array}$} & 16 & $\begin{array}{l}\text { Trainee1 } \\
\text { (TEEN1) }\end{array}$ & Female & \multirow{2}{*}{$\begin{array}{l}\text { No prior experience in } 3 \mathrm{D} \\
\text { modeling } \\
\text { No prior experience in } 3 \mathrm{D} \\
\text { modeling }\end{array}$} \\
\hline & & & 16 & $\begin{array}{l}\text { Trainee2 } \\
\text { (TEEN2) }\end{array}$ & Male & \\
\hline \multirow{2}{*}{$\begin{array}{l}\text { Modeling-Grp2: 3D } \\
\text { modeling group 2; } 2 \\
\text { members } \\
\text { Modeling-Grp3: 3D } \\
\text { modeling group 3; } 2 \\
\text { members }\end{array}$} & \multirow{2}{*}{$\begin{array}{l}\text { A spacious } \\
\text { lecture room at } \\
\text { the University } \\
\text { next to the } \\
\text { FabLab }\end{array}$} & \multicolumn{2}{|l|}{$\begin{array}{l}\text { 3D modeling; collaboration with } 16 \\
\text { the Virtual reality game group }\end{array}$} & $\begin{array}{l}\text { Trainee3 } \\
\text { (TEEN3) }\end{array}$ & Male & $\begin{array}{l}\text { No prior experience in } 3 \mathrm{D} \\
\text { modeling }\end{array}$ \\
\hline & & & 16 & $\begin{array}{l}\text { Trainee } 4 \\
\text { (TEEN4) }\end{array}$ & Male & $\begin{array}{l}\text { No prior experience in } 3 \mathrm{D} \\
\text { modeling }\end{array}$ \\
\hline \multirow{4}{*}{$\begin{array}{l}\text { Printing-Grp: 3D } \\
\text { printing group; } 4 \\
\text { members }\end{array}$} & \multirow[t]{4}{*}{$\begin{array}{l}\text { University } \\
\text { FabLab }\end{array}$} & $\begin{array}{l}\text { 3D printing; collaboration } \\
\text { with different groups }\end{array}$ & 15 & $\begin{array}{l}\text { Trainee5 } \\
\text { (TEEN5) }\end{array}$ & Female & $\begin{array}{l}\text { No prior experience in } 3 \mathrm{D} \\
\text { modeling }\end{array}$ \\
\hline & & $\begin{array}{l}\text { Instructing } 3 \mathrm{D} \text { printing and } \\
3 \mathrm{D} \text { modeling groups }\end{array}$ & 22 & $\begin{array}{l}\text { Main } \\
\text { Instructor }\end{array}$ & Male & $\begin{array}{l}\text { Experienced: first was a } \\
\text { club member, then } \\
\text { became the club } \\
\text { instructor }\end{array}$ \\
\hline & & $\begin{array}{l}\text { Assisting in instructing 3D } \\
\text { modeling and 3D printing } \\
\text { groups (also, main instructor } \\
\text { for robotics group) }\end{array}$ & 18 & $\begin{array}{l}\text { Assisting } \\
\text { Instructor }\end{array}$ & Male & $\begin{array}{l}\text { Experienced: was first a } \\
\text { club member, then } \\
\text { became the club } \\
\text { instructor }\end{array}$ \\
\hline & & $\begin{array}{l}\text { Designing the activities, } \\
\text { participant's recruiting, } \\
\text { observing the instructors \& } \\
\text { providing feedback to them }\end{array}$ & 35 & $\begin{array}{l}\text { Pedagogical } \\
\text { Expert }\end{array}$ & Female & $\begin{array}{l}\text { Experienced: Master of } \\
\text { Arts in education, club } \\
\text { instructor, club's } \\
\text { pedagogical expert }\end{array}$ \\
\hline
\end{tabular}

relaxed manner. Moreover, following the nexus analysis approach, we referred to our notes and pictures during the interviews to help the interviewee remember some specific events. This was needed only in few instances, though, since the events were fresh in the interviewees' minds. At the end of our discussion, we gave each young participant a movie ticket, a copy of the interview questions and a notebook for writing a freeform reflection, and we asked them to take pictures of their notes and email them to us if they wanted to.

\subsection{Data Analysis}

To gain a general understanding of "what was going on" in the case data, and more specifically, to make sense of the novice learners' self-directed-collaborative engagement in 3D modeling and 3D printing activities we combined thematic analysis [9] with nexus analysis, following the nexus analysis field guide [78]. The first author of this study first got familiar with the observation data and interview transcripts through reading them. In the second phase, the initial codes across the entire dataset were created through a thematic analysis of the data. In the third phase, for the sake of refining more subtle features of our data, she engaged with the literature specifically focused on the empirical studies of 3D modeling and 3D printing activities for children. In the fourth phase, she engaged in analyzing the nexus of practice, to understand what factors shaped the activities. This was done using by mapping the related semiotic cycles of persons (historical body, e.g., innovative,

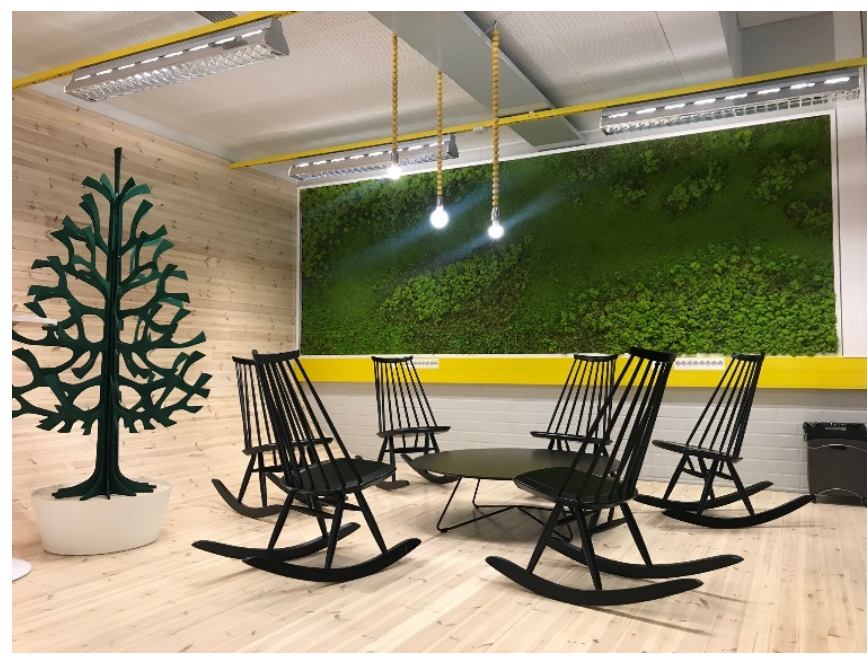

Figure 1: The room, located at the university, used for conducting the interviews with the Young People

habitual action, link of the practice to the uniqueness of the participant, emotional impact on the participant of this action, etc.), overt discourses (the interaction order: talks and image making of people as, e.g., conversational pairs, learner-learner, learner-instructor, etc.), automatic and unpracticed actions (place and its effect on 


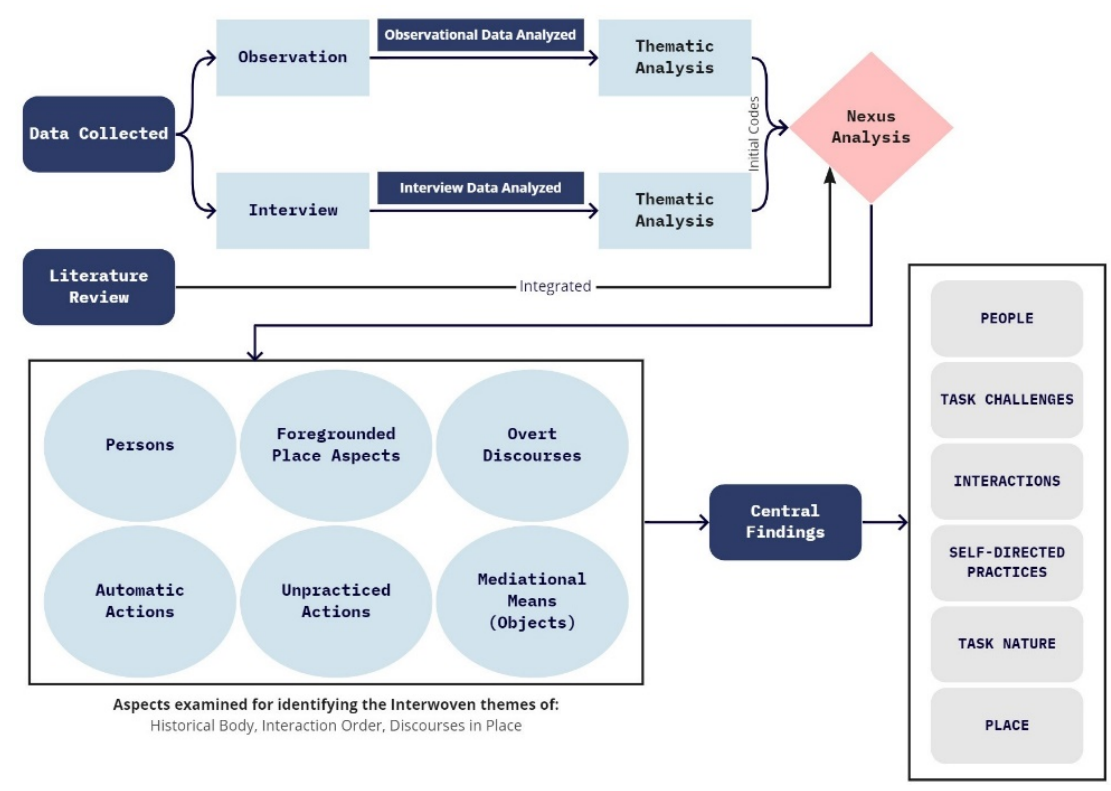

Figure 2: Analysis flow diagram

actions, collaborative skills, task difficulty, socializing, complex task structure, decision making power in this environment, vs. school, attitude toward (independent) learning, failure, problem solving skills, etc.), and mediational means (objects such as 3D modeling software and 3D printing and their history for this action). This resulted in a number of additional codes for the dataset. From this, in the final phase of the analysis, two issues - place and task emerged as central from the viewpoint of this paper, intertwined with the historical bodies of all participants (what knowledge and experiences they had or did not have), interaction order between them (in which ways they interacted or did not), and the discourses in place (how the place silently guided the actions of the participants into certain directions). See Figure 2 for a flow diagram for the data analysis.

The analysis was done by notebook, paper sketching, drawing digital diagrams, word document, and excel. Validity of the analysis procedure was ensured by discussing the results and ways of doing analysis via three different workshops in different phases of the study together with the other authors of this study, who are experts in the methodology used in the study.

\section{FINDINGS}

Following the nexus analysis field guide by Scollon and Scollon [78], we examined the speech of the participants, actions submerged in the historical body of the participants or unpracticed actions, discourses submerged in the design of built environment, utilized technologies as mediational means, and our own speech, writing and images as the material in conducting the nexus analysis. Our analysis foregrounded six themes with two central issues: place, task (task nature and task challenges) were in the center and people, interactions, and self-directed practices were interwoven with these. The themes were associated with the participants' historical body: their prior experiences in 3D modeling/printing and prototyping, their motivation for participating in the activity, their initial interest toward the activity, the unpracticed action of self-directed learning, group work and decision making, the submerged practice of dependent learning, and unpracticed skill of complex problem solving. Furthermore, the structure and nature of the task as well as the utilized technologies were involved: heavy task, boring task, task that needs long waiting time, and nature of the technologies that might facilitate or hinder the collaborative work. The themes were linked to the discourse of the design of built environment: the ways that the participants learnt, felt and interacted in this built environment. All in all, we uncovered how objects, environment, and historical bodies of the participants influenced the interaction order among the participants in different forms: engagement/disengagement in the task, ways of dealing with the challenges, ways of interacting with the mediated technologies, ways of decision making, ways of working in group, position taking (e.g., expert, savior, school children, etc.) and feelings about the activity, learning, environment and people. Next, we will go deeper in our findings.

\subsection{People and Their Interaction Orders and Historical Bodies Intermingled in the Social Action}

In our analysis, we tried to understand the historical bodies of the participants, relevant to the action, by uncovering why the participants decided to engage in the activity, how habitual or innovative the action-practice was for them, how the action was linked to the place, other practices, and participants' uniqueness and emotional valence. Accordingly, the analysis informed us about the prior experiences of the young participants, their motivation for participating and their initial interest toward the activity as well as their feelings and attitude toward doing and (independent) learning. 
The trainees were novice learners who lacked prior experiences not only in this type of activity, but also in working, mainly on their own, in such environment and setting. They had varying initial interests towards the program and activities, including friend's (TEEN2) or father's (TEEN4) influence on the participation as well as own interest in working with technology (TEEN3), machines (TEEN5) and designing (TEEN1). TEEN5: "My friend was here last summer, and she said this was a very nice place and I just like to work with machines. Like the 3D printers and stuff like that. That's why I'm here." TEEN4: "Well I have just watched, my father who [...] does 3D modeling and [...]. So, I have watched 3D modeling a little bit from the side. It's actually why I ended up applying for this $3 D$ modeling thing." TEEN2: "A friend of mine [...] said that he will probably apply for this program and I looked it up myself and then we decided to apply together."

In regard to the trainees' attitude towards independent learning associated with the amount of help they preferred to receive, only one of them (TEEN3), with a special interest and other types of technology-related prior work experiences, acted mainly on his own and built a kind of professional worker identity. However, the others, besides being pleased with the setting letting them learn independently, believed it was better if they had received more help. TEEN1: "it sometimes left us in a mild state of panic, "wait, what are we going to do now, what is this thing"'. TEEN2: "So, I don't really know how to use it. So, not always but sometimes it felt like they left too much for us to figure on our own. There came these problems we didn't really know what to do." TEEN4: "Maybe only, since I was a first timer and didn't really know the things [...] I didn't really get help or at least it felt like that a little." TEEN5: "The printer got stuck and he was helping the other groups and we had to wait like 20 minutes for his help." Some of the trainees showed persistency in doing and learning, while some tended to disengage easily. Moreover, some of them seemed to be excited to learn and some sounded bored.

Observing the interaction order, which the participants mutually produced among themselves, enabled us to examine talks and image making. The young people were interacting with each other and their instructors in different ways. Sometimes they were conversational pairs who engaged in friendly and off-topic conversations by talking about hobbies, game and school-related stuff, and sharing their stories; sometimes, they were group mates, who learned together and helped each other; sometimes some were experts who taught things to the others; sometimes some were saviors who shouldered the most of the group responsibilities; sometimes they were individuals who minded their own tasks mainly independently; and sometimes some were just school-aged children who disengaged when the task was challenging and there was no direct help or supervision. In the next sections, we elaborate on different identified sources of engagement/disengagement of these young people while involved in their tasks.

\subsection{Challenges of 3D Modeling, 3D Printing, and Digital to Physical Workflow}

In our study, the youngsters were responsible to explore interacting with the software, tools and machines mostly independently and without the continual direct interventions from the instructors, which might be necessary for achieving success in these types of activities [30]. By identifying a considerable number of occasions when the trainees sought for help, we explored the challenges of 3D modeling, 3D printing and digital to physical workflow by pinpointing those moments when youngsters needed particular support from their instructors. These events of help seeking are summarized in Table 2. By 'digital to physical workflow', we place emphasis on both rapid prototyping by converting the 3D model to a $2 \mathrm{D}$ design and then using mainly laser cutter to make it, and also creating the designed object using $3 \mathrm{D}$ printer. These challenges showed in the actions which were not submerged into practice by long habit for the young participants, i.e. they did not have those as part of their historical bodies: The young people needed to engage in a new action of 3D modeling/printing that was mediated by unknown technologies for them (3D modeling software and 3D printer). They also needed to act in a newly self-directed manner. That demanded their heavy involvement in problem solving without direct support from the instructors, which led them to experience failure and, due to that, frustration. None of these activities (learning new software/tools/machines independently, complex problem solving and failure as a common option) were part of their historical bodies, i.e., internalized as practices for these youngsters due to the school system and structured instructions that they usually received for learning at school.

In the immense world of digital fabrication, it is normal that even the instructors lack some relevant knowledge as part of their historical bodies. In the identified help-seeking events, there were several occasions when the instructors had no explicit immediate idea or suggestion for solving the issues, which occasionally led to a more complex situation for the youngsters. Furthermore, although providing pupils with a variety of approaches for 3D modelling might preserve their engagement [4], this variety makes it extravagant to expect an instructor having gained expertise or even experience with all of the tools and software. This was the case with TEEN3 from Modeling-Grp2. He chose to use a 3D modeling software in which his instructor could not help him much, because he didn't have enough experience with it. In the interview, this teen said: "So, like, he taught me the very basics then I learned from there. And then I asked him for help, many times when I couldn't figure out something. But he also didn't use Blender very much [...] so I... most of the time did Google how to use Blender. So, I learned that way mostly."

After the main instructor, who was attached to the groups, initially taught each group separately the basics and principles of either 3D modeling (Fusion 360) or 3D printing (mainly working with Pro2 by Raise3D), the group members explored the software and/or machines before starting their main tasks. The main task for Modeling-Grp1 was creating some parts of an Iron Man themed power suit/armor, which was done by sketching their ideas on paper, 3D modeling and fast prototyping using laser cutter and some electronics production tools such as soldering. Modeling-Grp2 and Modeling-Grp3 engaged in merely 3D modeling some objects (e.g., submarine) for the use of VR-game-group by utilizing 3D modeling software such as Fusion 360 and/or Blender. Printing-Grp reigned operating the 3D printer by taking care of 3D printing the models created by the other groups as well as identifying and solving the hardware and software issues with the 3D printer.

Modeling-Grp1, which was heavily involved in problem solving, confronted two main challenges of: 1 . transforming their paper 
Table 2: Help seeking events

\section{D Modeling}

Getting ready with the accounts and software | Difficulties in shifting from paper sketches to the digital design | Confirming the 3D model with the instructor before sending to the 3D printing group | Lack of design ideas and solutions to the problems | Saving issues with the software | Measurements and calculations | Design limitations for 3D printing | Difficulty in using some tools of the 3D modeling software | Constant failing and re-designing | Online help-seeking

3D Printing

Setting up the laptop | 3D printer was not working | 3D printer calibration | Layers were not being printed correctly | 3D model refuses to be printed $\mid$ 3D printer was working slow | Design file format was not suitable for 3D printing | Confusion in choosing the proper type of material for 3D printing | 3D printer stand was not stable enough | How 3D printer setting affect the output | Setting up the support material | Adjusting settings for a new material | overlooking finishing process | Failure due to the model measurements | Printing multiple objects at the same time | Print task prioritizing | Online help-seeking

Digital to Physical Workflow

Preparing the 3D model for laser cutting | Laying out parts in the software to avoid waste of material | How to operate the laser cutter | Choosing or finding suitable tools for assembling the prototype (e.g., screw, bolt, BoxCutter and sawblade) | Double checking with the instructor before operating the laser cutter by themselves | Laser cutter settings | Laser cutter did not cut through | Electronic related tasks for building the prototype (e.g., soldering and working with solenoid) | Modifying the 3D model or re-designing due to the 3D printing failure $\mid$ Modifying the model or re-designing due to the lack of expected functionality of the 3D printed part | Online help-seeking

sketches into a 3D digital design while having difficulties in understanding and utilizing some of the 3D modeling software tools, and 2. ideating a new solution and re-designing for improving their failed prototype. Moreover, since they were working with not only the modeling software, but also the laser cutter and electronics production tools for fast prototyping, they needed help with these tools and machines as well. A piece of describing observation fieldnote around Modeling-Grp1 says: "The instructor starts instructing the group on how they could now start manufacturing their 3D model parts. Instructs them to download new software. While waiting they talk about off-topic subjects in a very friendly manner. They need admin rights to install new software so [...] Jokes about how Ctrl $+S$ for saving is the most important thing when working with demanding software like modeling software since they can crash a lot. [...] Instructs the group how they can now use the new software to get their models out in the right format for the laser cutter. [...] Has some issues with the saving since the software isn't allowing them save every part of the model."

In Modeling-Grp2 and Modeling-Grp3, which engaged in individual 3D modeling some VR game assets, their main interactions with their instructor happened initially to learn basics. After learning the basics and principles, we found them in the vicinity of comfort with their job while they were addressing the confronted issues mainly via online help seeking, which is discussed to have its own challenges for independent 3D designing [29]. Related fieldnote about TEEN3: "he asked for help with an issue he was facing during the modeling [...] continuing independent work on the submarine model, had made clear progress on it and didn't seem to have issues that he couldn't solve himself with online help." In the interview, TEEN4 said: "Maybe there, that at least first timers could be helped. If someone already knows what to do, let them go at their own pace."

After learning the principles of 3D printing from their instructor, the Printing-Grp needed to deal with understanding the underlying reasons for the $3 \mathrm{D}$ print failure, which is also shown previously to be a source of disengagement [11]. The main challenge for them was adjusting the 3D printer setting as they had to: 1 . understand how their settings affect the output, 2 . change settings based on the model, and 3. adjust the setting for a new material. Related fieldnote about TEEN5: "She was working on a 3D printer in the FabLab. The main instructor went to help her but couldn't figure out the issue either, and instructed her to go ask for another instructor to help. She had looked for solutions online on the laptop beforehand. [...] She had started printing a part [...] but there was an issue with a layer not printing correctly [...] the main instructor joined and started discussing whether the process should be paused and fixed or if it would require a complete restart and instructed her to open up the model in the program to see if the problem could be identified in the code."

\subsection{Challenges Due to the Full Freedom in Formulating the Collaborative 3D Design Work}

The activities were arranged in a way that demanded the youngsters to both learn and do their jobs while they engaged in a task-based exploration. Here, the prominent emergent theme was self-directed collaborative practices; meaning, the youngsters, without the direct mediation of the instructors, took the initiative for formulating their collaborative activity. This brought challenges mainly for the 3D modeling groups. By holding the power of decision making, they engaged in open communications, idea sharing, task division, and time management activities. Here, the emerged findings are related to the historical bodies of the participants, both their automatic as well as unpracticed actions. Although collaborative activities are counted as automatic practices for the teenagers (e.g., at school), orchestration for shaping groups, task division, time management and the task structure are usually done by the adults (e.g., teachers). Therefore, for the purpose of fulfilling their tasks in this activity, these 


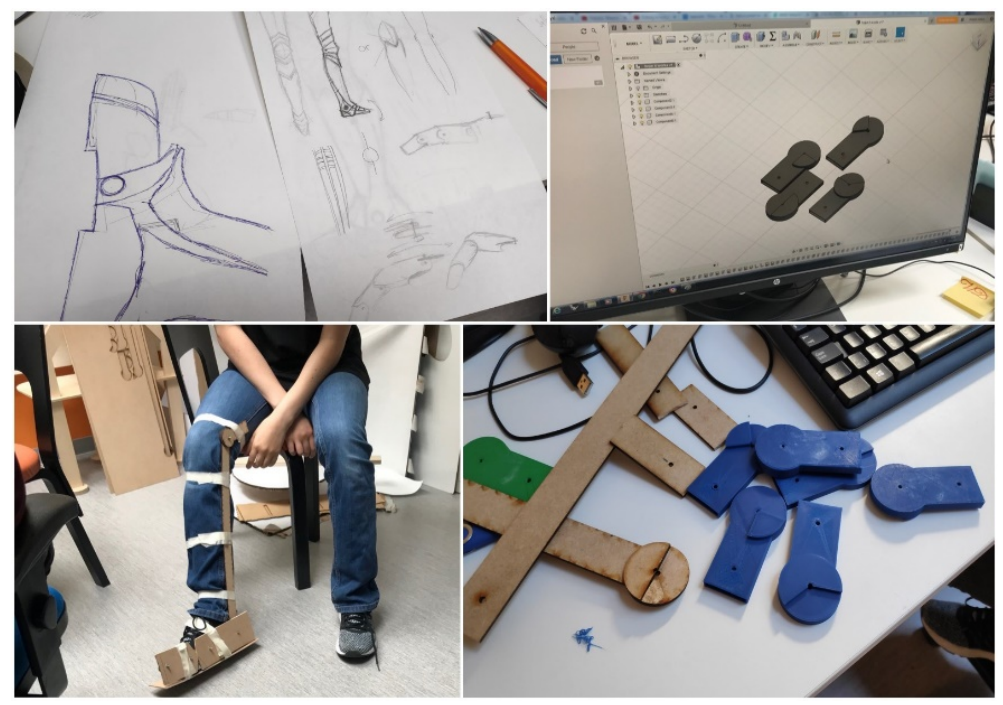

Figure 3: Paper sketch, 3D design, and laser cut wooden pieces as well as the 3D printed pieces (Modeling-Grp1)

young people were required to engage in some actions which were unpracticed for them, such as having the power of decision making for the matters related to their collaborative activities. The members of Modeling-Grp1 decided to work on each task collaboratively, while the members of Modeling-Grp2 and Modeling-Grp3 chose to work individually on different tasks. All the members lacked experience in these kinds of self-directed-collaborative practices.

From this perspective, the main challenge within Modeling-Grp1 was the matter of engagement and disengagement. TEEN1, as the most active and spirited member of the group, was shouldering most of the responsibilities including ideating, initial sketching, designing with the software, asking other member's feedback, supporting other peers, communicating with the instructor, and conducting the inter-group relations with the 3D printing group. Her role emerged as the savior of the group who was trying to carry things forward even in the challenging situations, while the other two members (including TEEN2) lost their motivations and got distracted by nonwork related activities such as playing game with their cellphones. Eventually, after a few days, the interaction order in the group ended with TEEN1 taking the leader role of the group, frequently engaging other members in the task by encouraging them to be creative, and also by asking for their inputs, ideas and corrections for different stages of the design. In the interview, TEEN1 said: "Well, it was a pretty good group considering that we got along. But occasionally it started to annoy a bit, because occasionally it felt that I was doing things and actually trying to get forward even though at some points I lost motivation for it, but with the others it might have went to just using their phones and yeah...”. A fieldnote describes Modeling-Grp1 like: "she keeps being the main sketcher for the group and talks a lot [...] doesn't try to force her ideas but wants confirmation from the others that they also think that her ideas could work. Asks others what their opinions are for [...] Tries to help out another group member with [...] has a minor disagreement about a certain angle in the design [...] laughs it off at the end of it." Figure 3 shows some activities of Modeling-Grp1.
On the other hand, in Modeling-Grp2 and Modeling-Grp3, where the members decided to work completely independent from each other on 3D designing different objects, the interaction order ended very different. The challenge of not experiencing the group work in a real sense happened. Although the group members were sitting at the same table and working together as a group on a same theme of work, their decision about working independently was one of the reasons that prevented them from having enough interactions with each other as group members who basically engage in different work or non-work related conversations. In the interview, TEEN4 said: "He worked on his own projects really and we worked basically on our own things. He even used the other program for his own thing." A related fieldnote about TEEN3 is: "Was still working alone on his models. [...] Was still working independently on his own models. Didn't seem to discuss much with others [...], without any input from other participants or instructors."

\subsection{Merely Designing or Merely Making Is Not Good Enough}

Our findings also shed light on the significance of the nature of the task and the technological mediational means which were crucial to the activities. The tasks were described for example as being heavy or boring, and waiting time for the task to be done as long. The nature of the utilized technologies submerged in the design of 3D modeling software and 3D printers were also affecting teenagers' engagement or forcing them to confront some challenges. The challenges that Modeling-Grp1 was confronting were not only 'not fun' to tackle with, but also tiresome to overcome. Based on our observations, we strongly relate this discomfort to the heavy nature of the digital to physical workflow that demanded the novice trainees to constantly bring their attention over a long period of time to the iterations among different stages of their 3D designing activity including ideating, problem solving, re-3D designing and re-making a prototype. In the interview, TEEN2 said: "Maybe, there were some boring times that we needed to wait for something, or we 

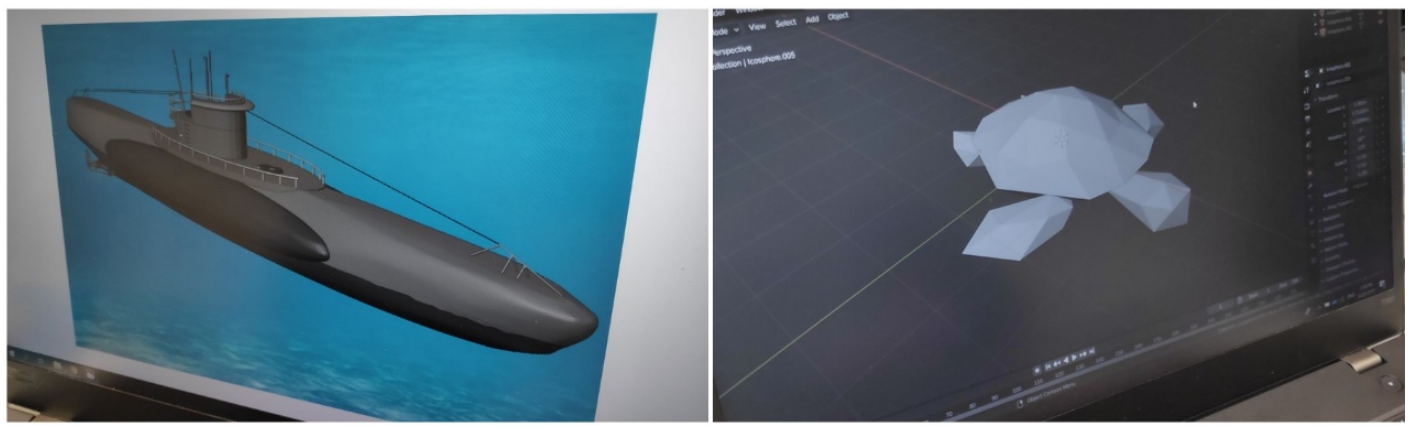

Figure 4: Game assets 3D designed by TEEN3 (on the left) and TEEN4 (on the right) for the VR-game.

didn't have any ideas. . it was the 3D modeling that was lots of just being on the computer and once we were done with that, we had to often wait that the printers can get it printed."

On the other hand, we witnessed an energetic atmosphere within the group engaging in the 3D printing activity. Interaction order in this group was relaxed and natural, within the group itself as well as with the other groups; they were working happily, playing around and yet having a care for the task in hand; they had fun while doing the task or even while facing the challenges. However, the major event of downtime for the members of this group was the waiting time for the 3D printer to print a model. In the interview, TEEN5 said: "I think there could be a little more like to do here. Sometimes it was a little bit just like waiting, so there could be a little stuff to do at that time."

As for Modeling-Grp2 and Modeling-Grp3, everything seemed to be too smooth and uninteresting while the members were engaging in merely $3 \mathrm{D}$ designing and literally individually for delivering game assets to the VR-game-group, without any specific interaction or close collaboration with that group. We do agree with [63] about the possibility of forgetting about the importance of other processes such as fabricating a prototype when being too focused on merely $3 \mathrm{D}$ designing on a computer. This was the case with the spirit of the assigned task to the youngsters in Modeling-Grp2 and ModelingGrp3, where they were not involved in the VR-game activity at all; wherein they could have the chance of being involved in utilizing their 3D creations in the VR-game and experiencing the enjoyment of giving lives to their designed objects. In the interview, TEEN4 said: "Well I mean, I liked being in the 3D modeler group, but I thought that next time I would try something else. For example, I looked at what the game group was doing, and it also looked pretty nice."

Furthermore, the 3D printer, together with the computer(s) connected to it, as the means mediating the task of 3D printing, and 3D modeling software as the means mediating the task of 3D modeling, were playing role in the youngsters' engagement. The 3D printer was possible to be explored by interacting with the machine as a group (e.g., one focused on the 3D printing settings, one explored the 3D printing materials, one checked the models, and etc.); on the contrary, cooperative work on one screen with a software for individual work either kept a youngster busy with design and left the other group members to be distracted by non-work-related stuff (Modeling-Grp1), or caused both groupmates working separately and disconnected from each other on the design of different objects
(Modeling-Grp2 and Modeling-Grp3); e.g., see Figure 4. I.e., it had a clear effect on the interaction order within the group. If one asks children, they might wish for the integration of collaborative features into 3D modeling software, as they did as such in [60].

\subsection{FabLab Providing a Cooler Place for Learning than a Lecture Room}

We examined the foregrounded aspects of the place where the activity was happening, including the place support or lack of it in relation to the participants' learning, feelings and interactions. These place-related aspects indicated how learning in that place was fun or boring or exciting, how the environment was relaxed, encouraging, or soulless, how the atmosphere was happy or uninspiring, and how the interactions were under control or out of control. The activities happened in both a FabLab (FabLab Oulu located at the University of Oulu) and a lecture room (located close to the FabLab); we found the former more stimulating and less boring compared to the latter.

The FabLab has two floors with several separate spaces for focusing on different activities: a making space located on the first floor with e.g., 3D printers, laser cutters and a vinylcutter; an electronics workstation for electronics-related work such as soldering; and a design space including a computer workstation (several desks and computer tables arranged in a U-shape with a big screen at the upper part of the $\mathrm{U}$ ) and a few rooms having doors opening to the computer workstation. For this program, one of the rooms in the second floor was arranged for the Printing-Grp, meaning, this group had their own private space and meanwhile were just close to the Modeling-Grp1 who also had the computer workstation mainly for themselves. Beanbags in the second floor were also useful for those moments that the trainees wanted to relax and be far from the computer screen. Two instructors were checking on these two groups either intermittently or upon each group's request.

In this FabLab environment, where there was more privacy and active group work, different kinds of interactions (pointed out in section 4.1.) were prominently accompanied by making jokes and laughing, which led to a positive atmosphere helping in lightening people's moods, especially when they were bored or stuck with the challenges; some indicating fieldnote quotes: "She and her team had kept working on the design, they had new ideas but they had identified some issues [...] Some of the issues were very major, like how 


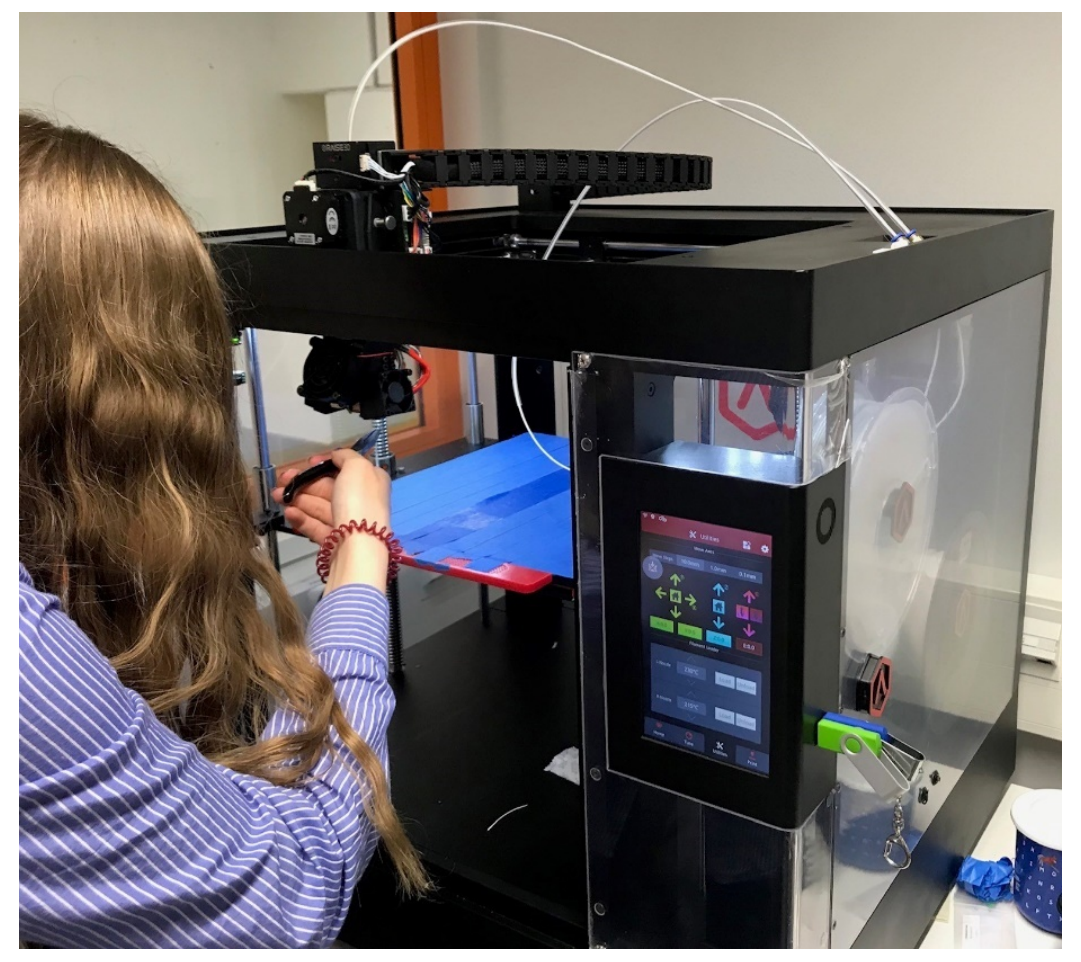

Figure 5: TEEN5 fixing an issue with a 3D printer

would the person get in the suit, but they were laughing and keeping a positive attitude about it" (Modeling-Grp1); "The instructor kept a very light mood and joked around a bit when facing a few technical issues and missing peripherals." (Printing-Grp). Conclusively, the physical arrangement and ambience supported an informal, fun and relaxing experiment in which the youngsters of Modeling-Grp1 and Printing-Grp could comfortably engage in the activity through wide and open group and inter-group interactions. "The instructor encouraged the $3 D$ printer and modeler groups to share ideas with each other [...] foked about how these teams are always blaming and cursing each other and how printers blame modelers and modelers blame printers" (FabLab). Figure 5 shows TEEN5 while fixing a 3D printer.

In the lecture room, located on the other side of the FabLab, the ambience was resembling the panopticon-style of a classroom with: a wide and flat space, several sets of chairs and tables for each group, relatively next to each other, wherein a set was belonging to our participants in Modeling-Grp2 and Modeling-Grp3. The instructors of different groups were sitting at the same lecture room, in row, next to each other and with a view toward the trainees but separated from them. On a corner of the lecture room a VR-game space was arranged enabling teenagers playing VR game in their free time. However, our participants from Modeling-Grp2 and Modeling-Grp3, as well as lots of other participants in the program did not engage in playing VR-game, although it was happening just next to them. Our participants in Modeling-Grp2 and Modeling-Grp3 sought help from their instructor rarely, and also did not make successfu cooperative work with each other or with the VR-game-group. Furthermore, the teens were exposed to lots of unwanted interactions with the others in case of leaving their workstation. Even while sitting at their workstations, they had no control over not being watched by the others. Interaction order in the room was constricted; the teens worked with minimal talk, movement or help-seeking. We take this in line of the previous findings on contextual condition as one of the factors which affects children's help-seeking behavior [65], and semi-private layout as influential in encouraging youths' participation [52]. We found the quietness of the atmosphere good enough to focus on the task in hand, but simultaneously heavy and free from fun and the necessary excitement where participants can engage and learn by heart. "He was approaching the instructor rarely and only if he was around and close to them [...] He didn't seem to discuss much with other modelers even though they were working around the same table" (Fieldnote about TEEN3). "The overall atmosphere seems to be pretty quiet. Instructors and participants seem to all focus on their own things." (Fieldnote about the lecture room)

\section{IMPLICATIONS}

This section introduces the research and design implications of this study.

\subsection{Factors Shaping 3D Modelling and 3D Printing Experiences of Children}

Our findings make clear that 3D modeling, 3D printing, and digital to physical workflow are challenging (see Table 2). Although rapid design-to-physical workflows open students' eyes to the realworld making constraints of what they are able to design almost 
limitlessly in the virtual space [22], for some of our participants, figuring out these limitations equaled to experiencing the challenges of understanding the design limitations itself, ideating a new solution to a problem, re-designing, re-prototyping and eventually waiting for the model to be 3D printed; the repetitive tasks in these types of workflows can be disengaging [11]. Although we showed that, interaction-wise, FabLab atmosphere led to more privacy, relaxed interactions and cheerful moments, on the other hand, from the task perspective, except seeing the young people's happiness when they had some improvements in their prototypes, we found not only they did not enjoy the task in a literal sense due to being too demanding and challenging, but also those who lacked primary remarkable motivation or interest in the activity disengaged easily. The freedom of the task division without the approval from any adult expert led to either imbalanced task distribution among the group members when they decided to work collaboratively, or member's disconnection from each other when they chose to do the tasks individually. Collaborative learning might expose children to the underlying collaborative process [28], but, based on our findings, does not necessarily engage them in the learning experience. Engagement/disengagement in the activities can be related to the reasons for participation and amount of interest in the activities. For example, the tedious task of merely 3D designing became uninspiring for a teenager who had no remarkable interest and experience in this activity, while another teenager who had considerable amount of interest towards the activity was eagerly engaging in it. The nature of the task considerably influenced the trainees' engagement or disengagement. The appropriate nature of the task, and keeping the balance between the structure of the task and its flexibility [94], as well as the right level of task complexity [70] are some of the crucial factors leveraging the success of the participants in 3D modeling. In addition to these, our findings highlight also the essentials of integrating fun and excitement in the structure of the task; because heavy task is tiring, merely 3D designing on a computer lacks excitement, and waiting time for 3D printing is boring. Finally, "Digital fabrication laboratories (FabLabs) influence how we think, ideate, do, make, and create." [23], and setting for making and tinkering activities is one of the values driving the behavior of the participants in supporting one another [90]. We explored the crucial foregrounded aspects to the social action under our study, by identifying two features of the available place support or lack of it: physical arrangement and ambience; as supportive social context are fundamental to children's successful experiences [94]. "There are very few 'pure' places in our worlds where everything in that place serves a single purpose and where there is nothing extraneous." [78]; we showed how physical arrangement and ambience in the FabLab were positively influencing the interactions and engagement of those groups working in there by providing them with different informal, relaxed and happy experiences; while, we could barely see active interactions and communications as well as exciting engagements of our participants in the traditional-panopticon-classroom-looking lecture room.

\subsection{Value of the Nexus Analytic Lens}

In this study, as suggested by Scollon and Scollon [78], we tried to set an approximate circumference of our participants (who they are and in which ways they interact with each other), the mediational means (which means they use for enabling their actions), discourses (overt discourses enabling interaction order as well as discourses internalized in the action), and place (available or lack of place support). To make our focus narrower, we looked our participants' engagement or disengagement in the social action; as these are essential characteristics in shifting a casual Maker's commitment to long-term learning [30]. The nexus analytic lens enabled us to approach digital fabrication and making activities, particularly 3D modelling and 3D printing, as a complex microcosmos, "as a multifaceted constellation of people, objects, tools, relationships, discourses, as a stage with particular performances" [33], within which complex configurations of interaction orders between participants, their historical bodies and discourses in place emerge and evolve. Based on our identified interwoven themes in this study, we highlight the significance of having a broader vision for engaging novices in digital fabrication and making activities. "The relationship between a person's perceptions, understandings, experiences of maker technology and the designs they create for maker technologies is likely to be highly complex area." [19]. A good example of that is TEEN4 in our study, as his situation can be described followingly: 'no prior experience in and no remarkable interest towards 3D modeling; the boring and difficult nature of 3D designing; working independent from the other group member; no significant discursive construction with the other group member; no close and direct instructions from the instructor; no involvement in any other activities; and, working in an uninspiring and soulless physical environment with minimum interactions with any tools or other people'. Nexus analytic approach helps in drawing together all these complex aspects, for a deep analysis of what is going on, as it encourages and guides the researcher to look beyond the surface, and also gives practical guidance for how to do that in its field guide [78]. Because of this, nexus analysis is suitable for studying complex topics as it enables in-depth studies considering comprehensive factors shaping the social action in question (social, historical, material). Nexus analysis is a flexible research strategy that can be used to address a variety of $\mathrm{HCI}$ topics with some sort of social action in focus (relating either to design or use of technology). It has been used in $\mathrm{HCI}$ previously for example for studying imitation and recycling in the design process [47], power and participation in a design project [35], and identity exploration and construction of children when creating video diaries of their technology use [34].

\subsection{Design Implications}

Our study offers a number of considerations for the designers of activities, spaces and tools associated with 3D modelling and 3D printing with children.

Regarding self-directing activities, lack of instructions can be problematic [74] particularly in case of pupils who lack experience in directing their own groupwork activities due to being used to the teacher-dependent school system, even though in exploratory learning people usually learn by trying out different methods such as trial and error and interacting with others. By linking young people's decision making power to the emergence of some groupwork challenges, we 1) underline the risk of uneven task distribution (see some similar examples of this type of collaboration challenges in 
digital fabrication and making activities produced in some prior studies [36, 83]), and also member's disconnection from each other, as well as 2) highlight the need for figuring out the best ways for supporting actors' self-directed interactions with each other when it comes to group collaboration-as this aspect of interaction has not been the focus of much digital fabrication studies. Sometimes "getting started with $3 D$ design software is a significant barrier for children" [29], which could be relatively smoothened by providing the participants with more initial instructions for the basics and principals of both 3D modeling and 3D printing, especially when they utilize expert tools, which might "come at too high of a cost in terms of learning" [10]-this worked nice in our study due to the enough amount of initial instructions and support.

Regarding nature of tasks, our study provides plenty of evidence of a wider spectrum of unpredictable challenges formed when the trainees engaged in CAD/CAM workflows, which "can be an accessible subject matter for students without prior experience in digital modeling or fabrication" [22]. Based on our findings, that support some prior studies, in doing the challenging task of 3D designing [51] right level of complexity [70], playfulness [66], and fun, which are some success criteria, should not be underestimated. Lack of careful consideration of "the appropriate nature and size of the task" [94] involved some of the trainee's heavily in problem solving to bring an idea to life, where there was a long distance between "what they have in their minds and their physical materialization" [56]. When it comes to 3D designing in alignment with fast prototyping and 3D printing, we underscore young people's engagement in all of these activities in an iterative manner; for overcoming the challenges of boredom and disengagement due to the boring and challenging task of merely 3D designing, waiting time for the $3 \mathrm{D}$ printer to finish the object, and heavy problemsolving situation. Therefore, as design implications for the task and activity, we suggest the essential needs for:

- Identifying different possible roles that might emerge for the pupils during this process; for example in our study based on what they did we could say they acted e.g., as: Thinker, 3D modeler, Prototype Maker, 3D print operator, Trouble shooter and Peer helper. We found that specific attention should be paid to the difficulties of this workflow and consider a role, in which they could have moments of relaxation, refreshing, playing and having fun in between their other more serious roles.

- Careful formulation of young people's tasks to be done while taking each of their roles; in this essence, understanding the possible challenges that they might encounter in doing each of the tasks is required first and foremost. We highlight the essentials of considering the amount of prior experience in the similar activities and also the level of interest in these type of tasks as two important weights for balancing the scale of the task requirements.

- Taking into account the challenges of digital to physical workflow especially when it includes the fast prototyping phase, which is heavily involved with repetitive problemsolving situation; Our gained insight suggests that one possible solution is to smoothen the experience by providing an opportunity for the children to take part in playing different roles by switching among different tasks in an iterative manner. Developing gamified means for this purpose, such as mobile apps, and integrating these ideas into them might be a fun and playful way of engaging and learning for children.

The main take away from our suggestions regarding regulating 3D designing with 3D printing could be the emphasis on avoiding involving children merely in 3D designing. Our implications are applicable in other contexts; e.g., as another case in our study, 3D designing could be aligned with VR-game coding to give a chance to children for experiencing both forms, instead of merely one of them. Last but not least, our findings support some other HCI and CCI researchers discussing about difficulties in drawing a "line between "designed" and "made" artifacts" [27], "misconception that digital design and physical production are two discrete processes" [22], "interdependency between the different stages of a casual maker's fabrication workflow" [30], and sacrificing working with hands over making with hands when design and making are detached activities [64].

Design implications for the space/environment, we showed how the physical space and materials we work with as well as people we interact with affect the activities and the resulting experiences. We agree with Peschl and Fundneider [69] that innovation (as well as digital fabrication and making) "is intrinsically coupled with the environment" and suggest that the FabLab seems to offer a more suitable Enabling Space, where "architectural/physical, social, cognitive, technological, epistemological, cultural, intellectual, emotional and other factors are considered and integrated, aiming to support innovation activities" than a traditional lecture room. It seems the lecture room did not support the processes of creation or use equally to the FabLab (cf. [61]). So far, the influence of space on digital fabrication and making activities of children has not been extensively addressed. We also identified a relationship between the space and social interaction, supporting the views of Lee and colleagues [52] on the importance of careful physical design and layout of the space in inviting participation in the offered activities. In addition, we emphasize the importance of designing a FabLab space by considering separated sections for noisy machines such as laser cutters or industrial 3D printers. The idea of separated spaces for different themes of activities (electronics, laser cutting, designing, 3D printing, etc.) will also serve maintaining the privacy of the participants by minimizing the unwanted interactions. Moreover, it would be also useful to have large screens and flipchart boards, whiteboards, interactive walls, etc. as well as sitting areas and computers/laptops close to each set of machines with some careful physical structure which facilitates interactions with both the people and machines (instead of having merely a separated computer workstation for teaching everything). When the instructors are teaching how to use a machine to a group, usually only 2 or 3 people who are standing close enough to the instructor can clearly see what is happening; hence, the designers of the makerspaces should focus on bringing some solutions for arranging the physical setting to support teaching different machines to the groups; for example, use of cameras showing closely the machine interface on the big screens might bring good solutions.

Design implications for the 3D modeling software. Although there are some expressive design tools such as Teddy [32], UCube 
[51], KidCAD [20], TADCAD [85] etc., which enable children to create $3 \mathrm{D}$ models easier, sometimes the instructors of the activities (e.g., our instructor participants) are neither familiar with the childfriendly modeling software or just prefer using more professional and powerful tools in the activities. Therefore, in order to be able to support the young people, they suggest children using those higher-level tools which are more complicated than the software specifically tailored for children. Moreover, even the child-friendly tools could still be challenging to start with, especially when it comes to designing something from scratch based on the ideas sketched on the paper. To address this issue, we encourage the designers to consider improving the 3D modeling software with features for supporting the transition from a paper sketch to the 3D digital design intending for a smoother start for the novice learners including children. For example, it might be useful if the software processes the picture of the paper sketch and gives 1) simulation of how its three dimensional version would look like and 2) suggestions of what objects/tools could possibly be utilized for creating a 3D model of it. Our next design implication is regarding the childfriendly $3 \mathrm{D}$ to $2 \mathrm{D}$ model workflow for fast prototyping with the laser cutter which is an important stage in digital fabrication. Not all of the child-friendly software has such a feature and not all of those who have it are powerful enough in recognizing how to slice a $3 \mathrm{D}$ model to give a satisfactory $2 \mathrm{D}$ result. For example, if one tries to save even a simple box as SVG (a vector image format for two-dimensional graphics) in Tinkercad, it will result in only a 2D rectangle/square. It does not even generate different sides of the box. This example clarifies how irrelevant could the result of the $3 \mathrm{D}$ to $2 \mathrm{D}$ conversion be by utilizing the current child-friendly $3 \mathrm{D}$ modeling software. Therefore, most of the child-friendly 3D modeling software need essential enhancement for addressing the lack of powerful features for creating a 2D drawing from a 3D model for fast prototyping using a laser cutter.

Design implications for the $3 D$ printers. Model slicing is an important step which goes between the created 3D model and 3D printing. The novice learners encounter difficulty in understanding the concepts of slicing the 3D model and why, when and where to use the support material for their models. The incorrect use of support material leads to the print failure after waiting a significant amount of time for printing; and struggling with the print failure could be a source of disengagement [11]. Hence, child-friendly ways of understanding the logic for the use of support material as well as model slicing should be invented. Furthermore, understanding the logics of 3D printing is essential for an independent, optimal and beneficial use of 3D printers by children. For the young people, this knowledge might be ambiguous and boring to be gained via verbal instructions; instead, 3D printer makers could consider some quick and easy re-engineering features for dismantling some parts of the 3D printers which might make learning some critical principles of 3D printing more appealing for children.

\section{CONCLUSIONS}

By collecting data via interview and observation methods and engaging in in-depth analysis utilizing thematic analysis and nexus analysis, we made sense of the complex social action of 3D modeling, 3D printing and fast prototyping. By identifying a broad range of help-seeking events for these activities, we showed how challenging they are, and placed our emphasis on the demand for the active presence and help of adult experts in different stages of these activities. Furthermore, by zooming in on the people and their interactions with not only each other but also the machines, we first highlighted the problematic situations occurring due to physical arrangements, nature of tasks, and self-directing practices, and then, presented our practical suggestions for how to carefully take these considerations into account when it comes to the design of digital fabrication and making activities. We specifically underscored the essentials of keeping 3D designing activity in close alignment and relationship with other digital fabrication and making activities, to keep the challenging and tedious task of 3D designing smooth, playful, and fun, and consequently to keep children engaged in the activity. We encourage CCI researchers, interested in the topic under this study to think of the ways for conceptualizing clear correlations between the task and physical environment to provide support for the young learners.

As to the limitations of the study, this is an interpretive case study with a limited number of participants. However, the research design enabled us to gain rich insights and conduct detailed analysis on the intricacies involved in 3D modeling and 3D printing activities among young people. Interviewing the participants was done after the work period instead of continuously during the whole period. This may potentially affect how much the interviewees were able to remember what happened and why. We had promised passive observation to the organizers and the participants, and, as the young people were busy with their tasks (as their job duties), it just was not possible to collect data during their work period. Nevertheless, we managed to gain rich insights also this way; the experiences were still fresh in the participants' minds. However, interviewing the participants in-action might have developed lots of additional insights which are missing from this research. The two-weeks period with working 5 days/week and 7 hours/day sets its own limits to our study. It is a norm for summer jobs for the youth in Finland. Focusing for two weeks on quite challenging new topics was most likely burdensome, however, and particularly with all the challenges our participants faced, engagement and interest in the work could fade. On the other hand, this duration enabled the participants to concentrate on the activities and carry out relatively complex tasks. An even longer timespan would have allowed for more time for reflection and learning. Noteworthy is also that this study included teenager participants engaging in possibly their first summer job. This is different to most of the CCI studies and some findings might be specific due to that. The work context also potentially brought new issues to play, compared to a hobby or educational context. Because this was work for the teens, they possibly took it more seriously and showed professional attitudes. With hobby or education context, we speculate that inability to create what was expected might feel a failure in a lower degree compared to the work context, and this might affect interest and motivation. This is an interesting possibility for the future studies, to find out how to arrange this kind of programs that compare work or hobby and student recruitment. Important is to note that the study was conducted within a particular cultural context, in the city of Oulu in Finland which naturally influences the results. Historical bodies of the participants and interaction orders among them are culturally 
shaped, even if we claim many of our findings do apply in the other cultural settings as well: with young people initially engaging in digital fabrication and making activities.

\section{ACKNOWLEDGMENTS}

This research is connected to the GenZ project, a strategic profiling project in human sciences at the University of Oulu. The project is supported by the Academy of Finland (grant agreement No. 318930) and the University of Oulu. This research was additionally funded the European Union's Horizon 2020 Research and Innovation programme (grant agreement No. 787476, COMnPLAY SCIENCE) and the Academy of Finland (grant agreement No. 324685, Make-ADifference).

\section{REFERENCES}

[1] Bekker, T. et al. 2015. Teaching children digital literacy through design-based learning with digital toolkits in schools. International fournal of Child-Computer Interaction. 5, (2015), 29-38. DOI: https://doi.org/10.1016/j.ijcci.2015.12.001.

[2] Benbasat, I. et al. 1987. The case research strategy in studies of information systems. MIS Quarterly: Management Information Systems. 11, 3 (1987), 369-386. DOI: https://doi.org/10.2307/248684.

[3] Berman, A. et al. 2018. Exploring the 3D printing process for young children in curriculum-aligned making in the classroom. IDC '18: Interaction Design and Children (2018), 681-686.

[4] Bhaduri, S. et al. 2019. Designing an informal learning curriculum to develop 3D modeling knowledge and improve spatial thinking skills. Conference on Human Factors in Computing Systems - Proceedings (2019), 1-8.

[5] Blikstein, P. 2014. Digital Fabrication and 'Making' in Education The Democratization of Invention. FabLab. transcript Verlag.

[6] Bourdieu, P. 1984. Distinction: A social critique of the judgement of taste . Cambridge MA, Harvard University Press.

[7] Bratteteig, T. 2003. Making change: Dealing with relations between design and use University of Oslo, Norway.

[8] Bratteteig, T. et al. 2016. The Life and Death of Design Ideas. COOP 2016: Proceedings of the 12th International Conference on the Design of Cooperative Systems. Springer International Publishing. 259-275.

[9] Braun, V. and Clarke, V. 2006. Using thematic analysis in psychology. Qualitative Research in Psychology. 3, 2 (2006), 77-101. DOI: https://doi.org/10.1191/ 1478088706qp063oa.

[10] Buehler, E. et al. 2014. ABC and 3D: Opportunities and obstacles to 3D printing in special education environments. ASSETS14 - Proceedings of the 16th International ACM SIGACCESS Conference on Computers and Accessibility (2014), 107-114.

[11] Buehler, E. et al. 2015. Inclusion and education: 3D printing for integrated classrooms. ASSETS 2015 - Proceedings of the 17th International ACM SIGACCESS Conference on Computers and Accessibility (2015), 281-290.

[12] Chu, S.L. et al. 2017. Fun in Making: Understanding the experience of fun and learning through curriculum-based Making in the elementary school classroom. Entertainment Computing. 18, (2017), 31-40. DOI: https://doi.org/10.1016/j.entcom. 2016.08.007.

[13] Chu, S.L. et al. 2015. Making the Maker: A Means-to-an-Ends approach to nurturing the Maker mindset in elementary-aged children. International fournal of Child-Computer Interaction. 5, (2015), 11-19. DOI: https://doi.org/10.1016/j.ijcci 2015.08.002.

[14] Le Dantec, C.A. 2010. Situating design as social creation and cultural cognition CoDesign. 6, 4 (2010), 207-224. DOI: https://doi.org/10.1080/15710882.2010.527009.

[15] Denzin, N. and Lincoln, Y. 2008. Introduction: The discipline and practice of qualitative research. The Sage handbook of qualitative research. SAGE Publications Ltd. 1-32.

[16] Digital Fabrication 101 | Formlabs: https://formlabs.com/eu/blog/digitalfabrication-101/. Accessed: 2020-09-14.

[17] Dlodlo, N. and Beyers, R.N. 2009. The Experiences of South-African High-School Girls in a Fab Lab Environment.

[18] Eisenberg, M. 2013. 3D printing for children: What to build next? International fournal of Child-Computer Interaction. 1, 1 (2013), 7-13. DOI: https://doi.org/10. 1016/j.ijcci.2012.08.004.

[19] Fitton, D. et al. 2015. Exploring children's designs for maker technologies. Proceedings of IDC 2015: The 14th International Conference on Interaction Design and Children (2015), 379-382.

[20] Follmer, S. and Ishii, H. 2012. KidCAD: Digitally remixing toys through tangible tools. Conference on Human Factors in Computing Systems - Proceedings (2012), 2401-2410.

[21] Freitas, J.L. et al. 2016. Methodological choices for research in Information Science Contributions to domain analysis. Transinformacao. 28, 1 (2016), 5-13. DOI: https://doi.org/10.1590/2318-08892016002800001.

[22] Gannon, M. et al. 2014. Teaching CAD/CAM Workflows to Nascent Designers. International Conference on Computer-Aided Architectural Design Research in Asia CAADRIA (2014).

[23] Georgiev, G. V. et al. 2017. A Framework for Capturing Creativity in Digital Fabrication. The Design fournal. 20, sup1 (Jul. 2017), S3659-S3668. DOI: https: //doi.org/10.1080/14606925.2017.1352870.

[24] Goffman, E. 1981. Forms of Talk . Philadelphia: University of Pennsylvania Press.

[25] Goffman, E. 1983. The Interaction Order: American Sociological Association, 1982 Presidential Address. American Sociological Review. 48, 1 (1983), 1. DOI: https://doi.org/10.2307/2095141.

[26] Gómez Puente, S.M. et al. 2013. Empirical validation of characteristics of designbased learning in higher education. International fournal of Engineering Education. 29, 2 (2013), 491-503.

[27] Grimme, S. et al. 2014. "We've conquered dark": Shedding light on empowerment in critical making. Proceedings of the NordiCHI 2014: The 8th Nordic Conference on Human-Computer Interaction: Fun, Fast, Foundational (2014), 431-440.

[28] Hamidi, F. et al. 2017. Using robotics and 3D printing to introduce youth to computer science and electromechanical engineering. Conference on Human Factors in Computing Systems - Proceedings (2017), 942-950.

[29] Hudson, N. et al. 2018. Investigating how online help and learning resources support children's use of 3D design software. Conference on Human Factors in Computing Systems - Proceedings (2018).

[30] Hudson, N. et al. 2016. Understanding newcomers to 3D printing: Motivations, workflows, and barriers of casual makers. Conference on Human Factors in Computing Systems - Proceedings (2016), 384-396.

[31] Hudson, S.E. 2014. Printing teddy bears: A technique for 3D printing of soft interactive objects. Conference on Human Factors in Computing Systems - Proceedings (2014), 459-468.

[32] Igarashi, T. et al. 1999. Teddy: A sketching interface for 3D freeform design. Proceedings of the 26th Annual Conference on Computer Graphics and Interactive Techniques, SIGGRAPH 1999 (1999), 409-416.

[33] Iivari, N. et al. 2020. "Arseing around was Fun!" - Humor as a Resource in Design and Making. (2020), 1-13.

[34] Iivari, N. et al. 2014. Video diary as a means for data gathering with children Encountering identities in the making. International fournal of Human Computer Studies. 72, 5 (May 2014), 507-521. DOI: https://doi.org/10.1016/j.ijhcs.2014.02.003.

[35] Iivari, N. et al. 2015. With best intentions: A Foucauldian examination on children's genuine participation in ICT design. Information Technology and People. 28, 2 (2015), 246-280. DOI: https://doi.org/10.1108/ITP-12-2013-0223.

[36] Iivari, N. et al. 2018. You have to start somewhere - Initial meanings making in a design and making project. IDC 2018 - Proceedings of the 2018 ACM Conference on Interaction Design and Children (2018), 80-92.

[37] Iivari, N. and Kinnula, M. 2018. Empowering children through design and making. PDC '18: Participatory Design Conference 2018 (2018), 1-12.

[38] Iversen, O.S. et al. 2017. Child as protagonist: Expanding the role of children in participatory design. IDC 2017 - Proceedings of the 2017 ACM Conference on Interaction Design and Children (2017), 27-37.

[39] Iversen, O.S. and Smith, R.C. 2012. Scandinavian participatory design - Dialogic curation with teenagers. ACM International Conference Proceeding Series (2012), 106-115.

[40] Jacucci, G. and Wagner, I. 2007. Performative roles of materiality for collective creativity. Creativity and Cognition 2007, CC2007 - Seeding Creativity: Tools, Media, and Environments. (2007), 73-82. DOI: https://doi.org/10.1145/1254960.1254971.

[41] Johnson, C. 2017. Toward computational making with madeup. Proceedings of the Conference on Integrating Technology into Computer Science Education, ITiCSE (2017), 297-302.

[42] Katterfeldt, E.S. et al. 2015. Designing digital fabrication learning environments for Bildung: IMPLICATIONS from ten years of physical computing workshops. International fournal of Child-Computer Interaction. 5, (2015), 3-10. DOI: https: //doi.org/10.1016/j.ijcci.2015.08.001.

[43] Kim, J. et al. 2015. A study to empower children to design movable tactile pictures for children with visual impairments. TEI 2015 - Proceedings of the 9th International Conference on Tangible, Embedded, and Embodied Interaction (2015), 703-708.

[44] Kinnula, M. et al. 2017. What if it Switched on the Sun? Exploring Creativity in a Brainstorming Session with Children Through a Vygotskyan Perspective. Computer Supported Cooperative Work: CSCW: An International fournal. 26, 4-6 (Dec. 2017), 423-452. DOI: https://doi.org/10.1007/s10606-017-9280-2.

[45] Klein, H.K. and Myers, M.D. 1999. A set of principles for conducting and evaluating interpretive field studies in information systems. MIS Quarterly: Management Information Systems. 23, 1 (Mar. 1999), 67-94. DOI: https://doi.org/10.2307/249410.

[46] Kristensen, T. 2004. The Physical Context of Creativity. Creativity and Innovation Management. 13, 2 (2004), 89-96. DOI: https://doi.org/10.1111/j.0963-1690.2004. 00297.x.

[47] Kuure, L. et al. 2010. Children imitate! Appreciating recycling in participatory design with children. ACM International Conference Proceeding Series (New York, New York, USA, 2010), 131-140. 
[48] Kuznetsov, S. and Paulos, E. 2010. Rise of the expert amateur: DIY projects, communities, and cultures. NordiCHI 2010: Extending Boundaries - Proceedings of the 6th Nordic Conference on Human-Computer Interaction (2010), 295-304.

[49] Lafreniere, B. and Grossman, T. 2018. Blocks-to-CAD: A cross-application bridge from minecraft to 3D modeling. UIST 2018 - Proceedings of the 31st Annual ACM Symposium on User Interface Software and Technology (2018), 637-648.

[50] Laru, J. et al. 2019. Designing seamless learning activities for school visitors in the context of fab lab oulu. Lecture Notes in Educational Technology. Springer International Publishing. 153-169.

[51] Leduc-Mills, B. and Eisenberg, M. 2011. The UCube: A child-friendly device for introductory three-dimensional design. Proceedings of IDC 2011 - 10th International Conference on Interaction Design and Children (2011), 72-80.

[52] Lee, V.R. et al. 2017. Supporting interactive youth maker programs in public and school libraries: Design hypotheses and first implementations. IDC 2017 Proceedings of the 2017 ACM Conference on Interaction Design and Children (2017), 310-315.

[53] Leinonen, T. et al. 2020. 3D Printing in the Wild: Adopting Digital Fabrication in Elementary School Education. International fournal of Art \& Design Education. 39, 3 (2020), 600-615. DOI: https://doi.org/10.1111/jade.12310.

[54] Lipson, H. and Lipson, H. 2007. Printable 3d models for customized hands-on education. Paper presented at Mass Customization and Personalization (MCPC) 2007. (2007).

[55] Litts, B.K. 2015. Resources, facilitation, and partnerships: Three design considerations for youth makerspaces. Proceedings of IDC 2015: The 14th International Conference on Interaction Design and Children (Jun. 2015), 347-350.

[56] Lorenzo, C. 2017. Digital fabrication as a tool for teaching high-school students STEM at the University. IDC 2017 - Proceedings of the 2017 ACM Conference on Interaction Design and Children (2017), 549-554.

[57] Loy, J. 2014. eLearning and eMaking: 3D Printing Blurring the Digital and the Physical. Education Sciences. 4, 1 (2014), 108-121. DOI: https://doi.org/10.3390/ educsci4010108.

[58] Magadley, W. and Birdi, K. 2009. Innovation Labs: An Examination into the Use of Physical Spaces to Enhance Organizational Creativity. Creativity and Innovation Management. 18, 4 (2009), 315-325. DOI: https://doi.org/10.1111/j.14678691.2009.00540.x

[59] Makhaeva, J. et al. 2016. Creating creative spaces for co-designing with autistic children - The concept of a "Handlungsspielraum." ACM International Conference Proceeding Series (Aug. 2016), 51-60.

[60] McNally, B. et al. 2017. Toward understanding children's perspectives on using 3D printing technologies in their everyday lives. IDC 2017 - Proceedings of the 2017 ACM Conference on Interaction Design and Children (2017), 298-303.

[61] Moultrie, J. et al. 2007. Innovation Spaces: Towards a Framework for Understanding the Role of the Physical Environment in Innovation. Creativity and Innovation Management. 16, 1 (2007), 53-65. DOI: https://doi.org/10.1111/j.14678691.2007.00419.x.

[62] Myers, M.D. and Newman, M. 2007. The qualitative interview in IS research: Examining the craft. Information and Organization. 17, 1 (2007), 2-26. DOI: https: //doi.org/10.1016/j.infoandorg.2006.11.001.

[63] Nemorin, S. 2017. The frustrations of digital fabrication: an auto/ethnographic exploration of '3D Making' in school. International fournal of Technology and Design Education. 27, 4 (2017), 517-535. DOI: https://doi.org/10.1007/s10798-0169366-z.

[64] Nemorin, S. and Selwyn, N. 2017. Making the best of it? Exploring the realities of 3D printing in school. Research Papers in Education. 32, 5 (Oct. 2017), 578-595. DOI: https://doi.org/10.1080/02671522.2016.1225802.

[65] Newman, R.S. 1990. Children's Help-Seeking in the Classroom: The Role of Motivational Factors and Attitudes. Fournal of Educational Psychology. 82, 1 (1990), 71-80. DOI: https://doi.org/10.1037/0022-0663.82.1.71.

[66] Ng, O.-L. and Chan, T. 2019. Learning as Making: Using 3D computer-aided design to enhance the learning of shape and space in STEM-integrated ways. British fournal of Educational Technology. 50, 1 (2019), 294-308. DOI: https://doi. org/10.1111/bjet.12643.

[67] Nishida, K. 1958. Intelligibility and the Philosophy of Nothingness. Maruzen, Tokyo.

[68] Norouzi et al. 2019. Interaction Order and Historical Body Shaping Children's Making Projects-A Literature Review. Multimodal Technologies and Interaction. 3, 4 (Oct. 2019), 71. DOI: https://doi.org/10.3390/mti3040071

[69] Peschl, M.F. and Fundneider, T. 2012. Spaces enabling game-changing and sustaining innovations: Why space matters for knowledge creation and innovation. MPRA Paper. (2012)
[70] Posch, I. and Fitzpatrick, G. 2012. First steps in the FabLab: Experiences engaging children. Proceedings of the 24th Australian Computer-Human Interaction Conference, OzCHI 2012 (2012), 497-500.

[71] Read, J.C. et al. 2013. Methods of Working with Teenagers in Interaction Design. Conference on Human Factors in Computing Systems - Proceedings (2013), 32433246.

[72] Read, J.C. et al. 2011. Understanding and designing cool technologies for teenagers. Conference on Human Factors in Computing Systems - Proceedings (2011), 15671572.

[73] Read, J.C. and Markopoulos, P. 2013. Child-computer interaction. International Journal of Child-Computer Interaction. 1, 1 (2013), 2-6. DOI: https://doi.org/10. 1016/j.ijcci.2012.09.001.

[74] Rieman, J. 1996. A field study of exploratory learning strategies. ACM Transactions on Computer-Human Interaction (TOCHI). 3, 3 (1996), 189-218. DOI: https://doi. org $/ 10.1145 / 234526.234527$.

[75] Schelly, C. et al. 2015. Open-source 3-D printing technologies for education: Bringing additive manufacturing to the classroom. fournal of Visual Languages and Computing. 28, (2015), 226-237. DOI: https://doi.org/10.1016/j.jvlc.2015.01. 004

[76] Schön, D.A. 1992. Designing as reflective conversation with the materials of a design situation. Knowledge-Based Systems. 5, 1 (1992), 3-14. DOI: https://doi.org/ 10.1016/0950-7051(92)90020-G.

[77] Schön, D.A. 1992. The reflective practitioner: How professionals think in action. Taylor and Francis.

[78] Scollon, R. and Scollon, S. 2004. Nexus analysis: Discourse and the emerging internet. Routledge, London

[79] Scollon, S.W. and De Saint-Georges, I. 2013. Mediated discourse analysis. The Routledge Handbook of Discourse Analysis. Taylor and Francis. 66-78.

[80] Sellen, A.J. and Harper, R.H.R. 2003. The Myth of the Paperless Office. MIT Press.

[81] Shewbridge, R. et al. 2014. Everyday making: Identifying future uses for 3D printing in the home. Proceedings of the Conference on Designing Interactive Systems: Processes, Practices, Methods, and Techniques, DIS (2014), 815-824.

[82] Silver, J. 2009. Awakening to maker methodology: The Metamorphosis of a Curious Caterpillar. Proceedings of IDC 2009 - The 8th International Conference on Interaction Design and Children (2009), 242-245.

[83] Smith, R.C. et al. 2015. Design thinking for digital fabrication in education. International fournal of Child-Computer Interaction. 5, (2015), 20-28. DOI: https: //doi.org/10.1016/j.ijcci.2015.10.002.

[84] Stickel, O. et al. 2015. 3D Printing with Marginalized Children-An Exploration in a Palestinian Refugee Camp. ECSCW 2015: Proceedings of the 14th European Conference on Computer Supported Cooperative Work, 19-23 September 2015, Oslo, Norway. Springer International Publishing. 83-102.

[85] Te, P. 2015. TADCAD: A tangible and gestural 3D modeling \& printing platform for building creativity. Proceedings of IDC 2015: The 14th International Conference on Interaction Design and Children (2015), 406-409.

[86] Thoring, K. et al. 2018. Creative environments for design education and practice: A typology of creative spaces. Design Studies. 56, (2018), 54-83. DOI: https://doi. org/10.1016/j.destud.2018.02.001.

[87] Tisza, G. et al. 2020. Patterns in informal and non-formal science learning activities for children-A Europe-wide survey study. International fournal of ChildComputer Interaction. 25, (2020), 100184. DOI: https://doi.org/10.1016/j.ijcci.2020. 100184

[88] Tuhkala, A. et al. 2018. Technology comprehension - Scaling making into a national discipline. ACM International Conference Proceeding Series (2018), 72-80.

[89] Ventä-Olkkonen, L. et al. 2019. A Literature Review of the Practice of Educating Children About Technology Making. IFIP Conference on Human-Computer Interaction (2019), 418-441.

[90] Vossoughi, S. and Bevan, B. 2014. Making and Tinkering: A Review of the Literature | InformalScience.org. National Research Council Committee on Out of School Time STEM.

[91] Vyas, D. et al. 2009. Collaborative practices that support creativity in design. ECSCW 2009 - Proceedings of the 11th European Conference on Computer Supported Cooperative Work (2009), 151-170.

[92] Wapner, C. 2015. Progress in the Making 3D Printing Policy Considerations through the Library Lens.

[93] Yeh, T. and Kim, J. 2018. CraftML: 3D modeling is web programming. Conference on Human Factors in Computing Systems - Proceedings (2018), 1-12.

[94] Zagal, J.P. et al. 2006. Social and Technical Factors Contributing to Successful 3D Animation Authoring by Kids. Georgia Institute of Technology. 